Nursing Inquiry Main document R1 1.5.18

\title{
A lifeworld phenomenological study of the experience of living within ageing skin
}

\author{
Abstract \\ Understanding people's experience of skin ageing as it is lived can enable sensitive approaches to \\ promoting healthy skin and to care in general. By understanding the insider perspective, what it is \\ like for individuals, a way to sensitise practice for more humanly sensitive care is offered. Through \\ interviews with seventeen, community-dwelling older people the essential meaning of living within \\ ageing skin was illuminated as a state of managed inevitability. The skin is inevitably changing, \\ ageing skin is a marker of change over time but the person within remains. Constituents of the \\ phenomenon comprise: the experience of unfamiliar sights and sensations given by ageing skin; \\ facing and accepting bodily changes and seeing this back and forth in family connections; taking care \\ of the skin 'to face' the world and to present oneself to others and a different place in the world, \\ same person, changed body. Findings point to why and how nurses can treat older people as \\ persons by not over emphasising a view on ageing bodies or bodies with aged skin alone, but in \\ tempering this view with deeper existential insights, meeting the older person with a skin care need \\ as a person and not just as a physical entity.
}


Nursing Inquiry Main document R1 1.5.18

\section{Introduction}

Worldwide the population is ageing with approximately 841 million people aged $>60$ in 2013 rising to over 2 billion in 2050 (United Nations, 2013). Maintenance of skin health in older age is an important but often neglected aspect of healthcare. Skin provides an essential protective barrier and sensory, thermoregulatory and vitamin D synthesis functions. As the skin ages it undergoes intrinsic and extrinsic degenerative changes (Cowdell et al., 2014). These affect both function and appearance. Impairment of skin function can make the skin significantly more vulnerable to damage (Voegeli, 2008).

At present most ageing skin research focuses either on aesthetics and cosmetics, that is appearance as opposed to function, or dermatological disease and skin breakdown. Examples include reviews of the risks of cosmetic surgery in the older population (Yeslev et al., 2015), age-associated skin conditions (Blume-Peytavi et al., 2016) maintaining skin integrity in older people (Kottner, Lichterfeld, \& Blume-Peytavi, 2013), the prevention and treatment of incontinence associated dermatitis (Beeckman, Van Lancker, Van Hecke, \& Verhaeghe, 2014) and pressure ulceration (Moore \& Cowan, 2015). The opinions and experiences of older people themselves have rarely been elicited although there has been some investigation into self-reported skin health in community-dwelling older people. Two epidemiological studies published in the last three decades have specifically investigated the prevalence of xerosis (dry skin) with reported prevalence of 7\% (Fleischer, 1996) 56\% (Paul et al., 2011) lack of detail about methodology limits robustness of these studies. Xerosis is often accompanied by the unpleasant sensation of itch (Cowdell \& Steventon, 2015). Medical assessment suggests prevalence of $\sim 50 \%$ (Adam \& Reilly, 1987) and anecdotal reports suggest this is a conservative estimate. Risk of skin tears increases with age (Carville, Leslie, Osseiran-Moisson, Newall, \& Lewin, 2014). As skin problems are often considered minor by both sufferers and health care staff, they frequently go untreated (Kirkup, 2008) despite causing discomfort and actual or potential impairment of skin barrier function. 
Nursing Inquiry Main document R1 1.5.18

To date little attention has been paid to how older people themselves experience the ageing of their skin. Qualitative studies have tended to focus either on the aesthetic aspects of female ageing or on skin disease or breakdown. For example Hurd Clarke, Griffin and Maliha (2009) discuss the strategic clothing choices made by older women to ensure that perceived transgressions in appearance, such as wrinkles and sagging skin, are covered. Similarly Hurd Clarke and Griffin (2008) write of older women's efforts to fight invisibility through their heavy investment in 'beauty work' of many kinds. These authors previously examined older women's experiences of natural and unnatural ageing and identified differing beliefs about efforts to mask ageing from acceptance to ageing being a phenomenon that should be fought against using all available help (Hurd Clarke \& Griffin, 2007). Liechty (2012) points to the complexity of women's relationship with their ageing bodies with a dichotomised state of contentment and desire for change. This thought is echoed within much of the allied literature. Existing phenomenological studies in this area are scarce. Macia, Duboz and Chevé (2015, p 174) considered the aesthetic body changes experienced by women aged 65-75 and uncovered the 'paradox of impossible beauty' discussing perceived stigmatising signs of ageing and the efforts that women make to minimise these. Phenomenological approaches have been used in the investigation of the experience of living with skin breakdown for example in pressure ulceration (Hopkins, Dealey, Bale, Defloor \& Worboys, 2006), chronic leg ulceration (Hyde, 1999) and chronic wounds (Goldberg, 2005). There is a substantial literature on the ageing body from differing perspectives. For example in an extensive online survey Hofmeier et al. (2017) uncover complexities in the way that women experience their ageing bodies identifying themes around the psychological and physical experience, injustices, inequities and challenges, the need for self-care and the desire to remain a valued member of society. Women's control over their ageing body and their ability to manage 'ageing body parts' using 'active mind' and 'busy body' strategies is revealed in a discourse analysis (Paulson \& Willig, 2008). A thought-provoking portrayal is offered by Hamilton (2016) in work entitled 'This damnable, disgusting old age' which examines concepts of ageing and 'being' one's body. 
Nursing Inquiry Main document R1 1.5.18

Related work concerns the experience of living in an ageing body. Bullington (2005) in a phenomenological study of 13 people aged $>60$ years explores the interaction between the individuals ageing body and their sense of identity discerning three distinct typologies: existential awakening, making it good enough and new possibilities. Bullington (2005) uncovered gendered elements to the lived experience with men all describing 'new possibilities' in which they expressed joy at the new freedom associated with ageing. Similarly in focus groups with people aged 65-92 years participants attached both positive and negative connotations to their ageing bodies (Jankowski, Diedrichs, Williamson, Christopher, \& Harcourt, 2016). Appearance was important as an indicator of capability and identity and there was an element of tension between 'growing old gracefully' whilst resisting changes in appearance. Appearance was a secondary concern and again men were perceived as being less bothered by their changing appearance (Jankowski et al., 2016). Whilst the norm in Western society may be to expect women to be more concerned about signs of ageing (Dumas, Laberge, \& Straka, 2005) the process of ageing can paradoxically be beneficial for some women (Macia et al., 2015). The notion of body-for-self and body-for-others again brings forth the duality of the experience of living with and ageing body and the differing perspectives experienced by older people in which they are continually challenged by a culture that attaches diminishing value to ageing bodies (McCormick \& Marie, 2008). Most qualitative studies focus exclusively on women, some include men in their sample but few focus entirely on males. One exception is a study of older men's perceptions of their bodies post-retirement (Drummond, 2003).

Whilst attention has been paid to the experience of living in an ageing body few studies have described the experience of living with(in) ageing skin. This understanding will offer a valuable contribution to understanding ageing phenomena and has potential to underpin humanly sensitive directions for practice. Deeper understandings of what it is like to experience growing older in one's skin offer a foundation for meaningful care of older people (Galvin et al., 2016). Our corporeal existence is an engagement with a complex world, such engagement is through this body which is 
Nursing Inquiry Main document R1 1.5.18

most often not consciously noticed by us (Merleau-Ponty, 1962). This includes the complex philosophical observation of an 'ecstatic' body 'out in the world' as a self, a self that is meeting all otherness external to it (Leder, 1992). All this constitutes a highly complicated situation that requires close attention in attempts to understand what it is like to live with(in) older skin and to influence skin care from such a standpoint. Leder $(1992$, p. 143) points to how a medical or objective view of the body, rooted in a mechanist model has made gains in interventions and treatments, but at the same time also has given rise to limitations and overly mechanistic ways of looking at the body. He analyses the usefulness of an alternative view, the 'lived body' and makes a case for the value of these understandings for medicine and healthcare: 'The ecstatic body is our surface, with its sensorimotor organs which are 'out' in the world'. In his seminal book, 'The Absent Body', Leder $(1990$, p103) discusses the body surface as part of a sensory motor system that is in-the-world: he explains in detail how through its surface the body projects outward to the world and at ... 'the same time it recedes from its own apprehension into anonymous visceral depths'. This philosophical foundation has significant import for nursing and for phenomenological research concerned with the meaning of ageing skin. Findings from such studies can be directly useful for practice. For instance, in the drive to humanise care (Galvin \& Todres, 2011), the centrality of maintaining skin health and the critical nature that the skin has on the individuals perceptions of themselves and others points to a need for greater understanding of the experience of living within an ageing skin and thus presents an opportunity to offer directions for a more humanly sensitive care.

\section{The study and its method}

The phenomenon of this study, the experience of living within an ageing skin, is examined and illuminated by the reflective lifeworld research (RLR) approach using the phenomenological epistemology advocated by Dahlberg, Nyström and Dahlberg (2007). Of particular importance was our desire to understand 'what it is like' for people from within their lifeworld (Toombs, 2001) as this is a firm foundation for health-related caring (Todres, Galvin, \& Dahlberg, 2014). Given that we are 
Nursing Inquiry Main document R1 1.5.18

both registered nurses, and our desire was to adopt phenomenological principles, we gave particular thought to the notions of bracketing, bridling and sensitisation.

Bracketing in descriptive phenomenology requires researchers to be aware of and to temper any impulse to frame data within their pre-understandings (Husserl, 1998). This is a putting aside of natural scientific knowledge, knowledge about measures or other hypotheses to be free to attend to how what is being examined, in this case the experience of living in an ageing skin, appears. Dahlberg (2011) offer a useful reflective procedure, whereby researchers to adopt a 'bridled' approach which is congruent with this epistemological openness that is a central hallmark of phenomenological studies. Dahlberg calls for researchers to be generally self-aware and reflective and to acknowledge their own views and experiences. In line with this we also followed the path of Hamill \& Sinclair (2010) and were consciously self-critical, self-aware and openly curious throughout the whole research process. However, in addition, initial pre-understandings were identified in terms of expectations of what may emerge as participants described their experiences. The interviewer (FC) adopted this open 'bridled' approach, remained disciplined to not go beyond the concrete features of the data, to allow the phenomenon to show itself in its own way and at its own pace (Dahlberg et al., 2007). This was a process of searching for and describing the meaning of living in an ageing skin, with its variations. The study was sensitised by phenomenologically oriented ideas about wellbeing as an existential phenomenon that can act as a resource within illness (Galvin \& Todres, 2011).

\section{Participants}

A purposive sample of seventeen community-dwelling older people aged 72 - 88 years, 12 female and five male were interviewed by FC. All were independent in their daily lives and has no current skin disease. This cohort was chosen as the focus of this study is concerned with 'normal' skin ageing. Recruitment was via advertisements and later word of mouth. Participants contacted the 
Nursing Inquiry Main document R1 1.5.18

researcher and were sent an information sheet. Any questions about the study were answered by the researcher and a mutually convenient time and venue to conduct the interview was agreed.

Interviews

Data were collected through a series of phenomenologically orientated interviews with 'well' older adults. The first question was broad 'can you tell me what it is like to experience ageing skin?' subsequent more probing questions that sought concrete examples and which were 'experience near', that is, they stayed very close to the experience of ageing skin were used (Todres \& Galvin, 2012). Participants were encouraged to give detailed descriptions and examples of what the experience was like for them. Interviews were conducted in participants own homes or on university premises as they chose. Four of the male participants chose to be interviewed alongside their wife. Participants were recruited and interviewed between December 2015 and March 2016. Interviews lasted from $11-114$ minutes and were audio-recorded and transcribed verbatim.

\section{Ethical considerations}

All ethical requirements for England were met. The study was approved by a university Research Ethics Committee (Reference number 198). Participants were reminded that interviews were entirely voluntary and that they were free to stop at any time without having to give an explanation. Written consent was given by all participants. The researcher was mindful that the interviews could evoke powerful emotions and was sensitive to this risk.

\section{Analysis}

The process of analysis involved both researchers and aimed to discover nuanced meanings emerging from the transcripts and required intense dialogue with the data. Understanding of the phenomenon, as a whole, and as parts was sought. This involved a back and forth process to allow a whole-detail-whole (Todres \& Galvin, 2008) perspective to emerge. The aim of the analysis was to 
Nursing Inquiry Main document R1 1.5.18

seek a pattern of meanings and eventually how these meanings connected and made sense of the general structure of the phenomenon. In this process the concrete and lived experience shared in the interviews were transformed into a phenomenological description of the experience of living with an ever ageing skin. The researcher, as a nurse researcher in skin health, adopted a bridled approach to the data analysis (see also example from Lindberg, Österberg, \& Hörberg, 2016). That is, existing professional and theoretical frameworks were set aside and the process of understanding was consciously slowed down, to avoid premature assumptions about what had been said (Dahlberg, Todres \& Galvin, 2009). The interview process was aimed to allow concrete descriptions to emerge, so that the focus was on the depth of what it was like rather than patient reports of their skin health. Initially the transcripts were read in full several times keeping an open mind. The purpose here was to become familiar with the data, the participants descriptions and to understand the data as a whole. A reflective analytical process aimed to explore what parts of the data revealed as the meaning of living with an ever ageing skin. Here 'bare bones' of the phenomenon were developed as data summaries that offer descriptions of major constituents. An examination of 'the parts' (variations described by participants and their meaning) followed in which the transcripts were interrogated to answer questions such as: how does this participant describe the phenomenon; and what is (s)he really saying in more general terms; is there something that is repeated through many variations and are there opposing statements that point to deeper meanings? Such guiding questions were devised to deepen the analysis of what it is like to live within an ageing skin and to provide an analysis of both the general structure of the experience and description of rich variations as described by participants.

\section{Findings}

The essential meaning of the phenomenon is presented first. This refers to the characteristics of the phenomenon that cohere, without which it would not be the phenomenon of living within an ageing skin. The essential meaning brings the constituent parts together and is the backdrop against which 
Nursing Inquiry Main document R1 1.5.18

these parts can be viewed (Johansson, Ekebergh, \& Dahlberg, 2009). The meaning of the phenomenon is further revealed in descriptions of the four constituents: $i$ ) the experience of unfamiliar sights and sensations given by ageing skin; ii) facing and accepting bodily changes and seeing this back and forth in family connections; iii) taking care of the skin 'to face' the world and to present oneself to others and iv) a different place in the world, same person, changed body. Exemplars from the transcripts are used to illuminate the meanings within constituent parts.

The essential meaning of living within ageing skin is a state of managed inevitability. The surface of the body is changing and these changes give rise to new sights and sensations. Externally the body is altered but the person within remains. Ageing skin is a marker of change over which people have limited control. It is experienced temporally in relation to their past, younger times and in the context of other generations both past and future; what people can see in themselves and in others. To live in an ageing skin means making choices about how to care for this most visible organ and how to present it to self and others. Changes in appearance mean beginning to have a different place in the world. Ageing skin is a sign of gradual decline and an outward display of increasing frailty and ultimately death.

\section{i. $\quad$ The experience of unfamiliar sights and sensations given by ageing skin}

The familiar surface of the body is ever changing, the changes give rise to new sights and sensations. Externally the body is altered but the person 'inside' remains. Participants described visible changes in their skin that were both seen from first and third person perspectives and changes that were also felt as various sensations such as 'crocodile skin', 'you notice how it peels you know, it's sort of like rhinoceros skin'. Boundaries of skin are broadly defined in participants' descriptions and included hair, nails and mucous membranes. Initial descriptions often concerned the more visible changes. Facial wrinkles are the first sign for many and can be interpreted as an indicator of ageing or as welcome laughter lines. Hands are also prominently featured, the skin becomes thinner and veins 
Nursing Inquiry Main document R1 1.5.18

more obvious, the skin loses elasticity and when pinched up takes longer to return to normal. These changes were experienced as negative to some whilst others were more sanguine 'oh, just the usual slight mottling that you get there's nothing that's causing any alarm'. Pigmentation changes, 'you become paler', almost invisible, skin colour is less even and brown patches, 'liver spots', begin to appear.

Changes noticed as altered sensation include the whole body, skin tends to become drier especially on the lower legs. For some this causes no problem but for others it leads to unpleasant sensations such as itch and it is visually unattractive 'ugly, scaly, flaky'. 'Bingo wings' are described by most female participants, the sight of saggy, 'papery' upper arms is a sure sign that they are getting older. For some their whole body had changed 'I've become what I call saggy'. Participants noticed more blemishes such as thread veins and varicose veins over time. Hair is a particularly visible part of ageing and mucous membranes may become dry, uncomfortable and more prone to damage. Medication can cause problems especially steroids and anti-coagulants which can lead to thinner, more fragile skin which is damaged more readily and repairs more slowly, 'you have got to be careful with what you do because the slightest knock produces a bruise that can take quite a while to go away'. Function of the skin was more important than how it looks, 'skin is good stuff, it needs to be, if it gets damaged it takes longer to heal and if it breaks you are in real trouble'. Participants became 'more aware of body as a whole, more aware of vulnerability' as they aged.

Associations were made between specific skin problems and risk. Participants who had encountered others who had experienced leg ulcers, though few in number, were particularly aware of the need to care for their skin and had a real fear of developing painful, slow healing ulcers themselves. This fear was a significant motivator to positive action in ensuring that their skin remained healthy predominantly through the regular use of moisturisers. The findings also revealed that the skin's appearance also opened up a deeper dimension that has to do with the intertwining of identity and 
Nursing Inquiry Main document R1 1.5.18

changing skin. For example, sometimes the skin ageing process caught them unawares; 'Sometimes you look in the mirror and think ah, or if you are in a shop and you go past somewhere and you think, it sort of catches you a bit unaware' Others simply avoid looking in the mirror as they do not like what they see.

Skin was not perceived as a separate entity or body part, but rather seamless with growing older, 'my skin is part of my older body so I would be more aware of respecting my skin, because the whole lot is getting older isn't it, the inners and the outers, so you have got to look after the outer bit I am more aware of your body being vulnerable I think I am aware of my body as a whole'. These changes are generally accepted by the participants as there is, in their view, no real choice, ageing is inevitable. However for most skin was a precious part of the body that needs to be protected. Skin performs an important function, it is essential for health and wellbeing, it 'covers my bones .... keeps it all in there'. The fragility of skin becomes more evident in growing older, it is more easily injured and slower to heal as noticed by participants. Changes in skin appearance also underlined its fragility and whole body changes.

ii. Facing and accepting bodily changes and seeing this back and forth in family connections Ageing skin is a marker of change over which people have limited control. It is also experienced in relation to one's own past and present and previous and future generations. Changes are often slow and there is a steady realisation that these are taking place over several decades, 'it was just a gradual realisation that the tension in the skin, particularly on the arms and on the back of the hands was beginning to wrinkle up, I used to pretend it wasn't happening but of course you can see'. For some there is a more stepwise decline or a sudden experience of ageing associated with traumatic life events. There is a perception of limited control over how the skin ages and an awareness and acceptance that it is 'happening to us all'. It was viewed as to some extent genetically predetermined and something that cannot be changed. Detailed accounts of how their skin ageing 
Nursing Inquiry Main document R1 1.5.18

followed the same pattern as their parents were provided 'well my Mum had them there [thread veins] .... and I've got them there'. Hair changes in terms of colour, texture and density were particularly seen as being familial. Participants described seeing their mother or father when they looked in the mirror. This was as expected for some but a tangible indicator of ageing and ultimately their own mortality for others.

Participants had begun to notice signs of ageing skin in their adult children with sons gradually balding and daughters beginning to wrinkle. Discussing baldness 'my dad used to say 'grass never grows on a busy street', so I'm obviously not very busy Bob's [participant's son] inheriting, he's what 42 now, he's going grey, but he's inherited your good head of hair, hasn't he, lucky lad'. Just as skin ageing was seen to follow a family pattern skin care practices were also seen to be influenced by younger and older generations, particularly in terms of mothers passing on their skin care habits to daughters.

iii. Making choices about how to care for this most visible organ and how to present it to self and others.

To live in an ageing skin means making choices about how to care for this most visible organ and how to present it to self and others. Participants described caring for their skin on a continuum with a medical notion at one extreme, concerned with comfort and protection to an appearance focus at the other, with an aesthetic emphasis. Care of one's skin is important but understandings of what constitutes care are wide ranging. To some care was keeping the skin intact predominantly by using moisturisers. Occasionally this was a regular routine with diligent use but for most it was a reactive measure if their skin felt dry or itchy 'will use stuff if uncomfortable'. Although many experienced dry and itchy skin few had sought medical advice; their suffering was too trivial to bother a doctor with. 
Nursing Inquiry Main document R1 1.5.18

Thoughts about appearance were more dichotomised and seemed in some instances to reflect longheld beliefs about the importance of looks. Of note, participants who described paying relatively little attention to their appearance were all husband and wife couples, suggesting social aspects. One pair described themselves as 'outdoorsey', with better things to do than think about how they looked; this was the dominant opinion in their peer group. Another couple had been academics and had always believed that they were not particularly attractive. However this was not a cause of concern as they were both intellectually very able and focused their efforts on maintaining brain function rather than 'beauty'. They suggested that they had little to lose in terms of looks, 'if you're sharp and bright you don't need appearance. if you've never been the top of the tree beauty-wise you've got less distance to fall'. The effort of skin care had become too much for one couple who had experienced health problems and they recognised that they had 'got very sloppy in our grooming habits'.

More participants, predominantly women, invested significant effort into maintaining their appearance. This was both for them to maintain their personal morale and as an important factor in facing the world, 'I have spent years creating a sort of image ... and I don't expect to let this slip now'. They were clear that keeping up their appearance was a vital part of wellbeing and that 'letting standards slip' was to enter a downward spiral 'if you don't bother you might as well be in a box'. They were accepting of the inevitable changes brought about by ageing and took steps to manage these however, there were some interventions that were beyond reasonable for all, for example 'botox' and cosmetic surgery. Descriptions of skin care routines ranged from a daily soap and water wash to quite complex regimens using multiple products. They considered that it is better to 'grow old gracefully than look ridiculous'. Each had their own boundaries of what was acceptable, for example some would never leave the house without their full 'face' on, 'I've never gone without makeup, from being, well just say I left school at 17, when I went to college I started wearing makeup and I've never not worn it you look better if you've got a little bit of something on your 
Nursing Inquiry Main document R1 1.5.18

face'. There was an association between skin care and maintaining your image for the outside world. Others kept make-up for more special occasions. Each had a clear notion of the desired and the possible in terms of appearance.

Descriptions about skin care included relatively little about bathing and cleansing habits and focused more on use of facial products, hand-cream and make-up. Choice of products was often limited by cost and lack of belief in claims made about product properties and effects. Products were selected with care and economy. Some participants described sticking with the same preparations for many years whilst others suggested that changing was positive 'you need to change products every so often otherwise your skin gets used to them'. Beauty care was often routine 'I have the morning ritual to start off the day looking the best I possibly can'. For some this was supplemented by occasional episodes of 'treats', 'luxury' and the opportunity to 'titivate', such as visiting a beautician or a spa.

Hair was a vital part of looking good and an unexpected emphasis. Hair was an important feature in descriptions of the experience of living with ageing skin. Hair thinning was experienced by both men and women. Most women visited a hairdresser regularly and had adapted as their hair colour faded with age, for example 'hair .... so important to keep it looking good, have to learn new ways to manage it, more flattering'. Nail care was of prime importance to some participants who felt 'undressed' if their nails were not well manicured and painted. Clothing had been adapted over time by some. Upper arms were a frequent area that women preferred to be covered citing the development of 'unsightly and flabby bingo wings'. Legs were also covered by some partly for protection of friable skin but more often for cosmetic reasons such as varicose veins and discoloured patches. Bodily hair declined noticeably over the years although for most men being clean shaven remained important and some women recounted how they managed depilation of facial hair, 'I am a 
Nursing Inquiry Main document R1 1.5.18

bit vain I have to admit, I now get my whiskers tweaked once a month ... the same person does my nails for me, and once a month I have a rinse put on my hair, because I didn't want it to go grey'.

Awareness of oneself as ageing was often noticed in the context of others such as close friends ageing. Participants made comparisons between themselves and other older people and even those that were not overly concerned with their appearance noticed ageing in others. 'I think it's only the last few years as we've all got older now but I had noticed that some of my friends skin has aged and wrinkled far more than mine has'. Thoughts about other older people ranged from acceptance that everyone is getting older to powerful feelings that others were letting the side down by not making the effort. One woman recounted of a friend 'I get this sudden urge that I would really like to sort of make her up'. Similarly another described 'when I see friends and they have got all wrinkles here, and it's even on their breasts. And I think what are they doing? And I think it's such a shame, letting themselves go'.

For some skin changes led to a new reluctance for others to see their skin 'I'm very self-conscious of my whole body skin. And I don't like taking my clothes off in front of anybody even my doctor who I love to bits'. Others were more philosophical, 'I'm happy in it, but I have accepted it, because at the end of the day, you haven't got a choice have you'. Some participants took care to cover particular parts of their skin, predominantly upper arms in women, but equally some carried on with their usual clothing habits and were happy for others to see them in shorts and swimming attire.

\section{iv. $\quad$ A different place in the world, same person, changed body}

Changes in appearance mean beginning to have a different place in the world and revealed aspects of temporality and living 'from the inside'. This was manifest as expressions of being the same on the inside but facing the world in a changed skin. A changing body externally, but consistency as this 
Nursing Inquiry Main document R1 1.5.18

person internally; 'I'm still me'. In some respects there is a confidence that comes with age 'well once you get older you think, well people have got to accept you as you are I think, you know?'

There was a desire for some to make the most of their appearance and a sense of 'not letting oneself go'. How others viewed their appearance was an important dimension and includes influence from peers and families to 'maintain appearances'. This included literal aspects, the physical skin, but also other ways of presentation to the world including, hair, clothing and make up. Participants adopted an attitude of 'growing old gracefully' although none felt old on the inside, it was just their body that was deteriorating over time. This was relatively easy to live with in some respects as with age comes increasing confidence and less need to 'measure yourself against others standards'. With friends the expectation was that they would grow old together and that appearance was immaterial but conversely participants were aware of signs of ageing in others and were critical when they were thought to be 'not making the effort' which was interpreted as 'letting go of life'. Parents were often encouraged by adult children to maintain their appearance. Whilst they described enduring acceptance with friendship groups and families, attitudes of wider society were more varied. Some participants portrayed a picture of being treated the same despite their age albeit with more, much appreciated, offers of help. Some thought they were viewed by others as 'just an old biddy', highlighting a more societal view of the potential to become increasingly invisible with age. Although participants were not keen to be labelled as old themselves there was a tendency to do this to strangers, for example wearing too much beige was considered a sure marker of ageing. There was a disconnect between their view of themselves and their friends as older but still the same whilst others were more inclined to be seen as 'the beige brigade', just a homogenous group of old people. Participants rarely thought of themselves as old but were acutely observant about other people, often of similar age, who they judged to be old 'it still comes as a bit of a surprise to me that people sort of acknowledge that I'm old my social life is spent with people of my 
Nursing Inquiry Main document R1 1.5.18

own age and we're all grouped together but we, none of us think we look like the other old folks that we see in cafés or out walking'.

Externally the body is altered but the person 'inside' remains. Participants experience living within an ageing skin. Some are content to let the process happen, others make efforts to conceal the changes but all have clear limits on the actions they are willing to take to look their best. They are encouraged by others and themselves encourage peers to make the effort and take care of their appearance. Paradoxically they see older strangers in a different way. The essence of living within an ageing skin is a state of 'managed inevitability', skin changes and people take different actions in managing but, but despite these external changes the person within lives on.

\section{Discussion}

One of the central insights of Merleau-Ponty (1962) is that we are our bodies and experience the world as this body. Merleau-Ponty differentiated body object and body subject in order to indicate how as humans we regard our embodiment at different times: sometimes as if it was an objective entity independent of ourselves, and at other times, a body subject where meanings are lived and experienced from within. Leder's (1990) philosophical work delineating the absent body unfolds these ideas further. Such philosophical insights are highly relevant to our findings as older people regard their skin both as body object as surface skin changes are manifest, and at the same time they regard their ageing skin in more subjective ways with relational connection to the past, others and sense of self . For the most part the skin has 'a silent' presence until something about it is changed. We take these philosophically informed aspects into account, because human existence concerns a complex variety of intertwined dimensions it is important to note and unfold these, to make an additional 'reflective move', and to further examine the findings in the context of the lifeworld in hand with relevant empirical research literature. Lindberg et al. (2016) make a case for further examination of findings in the light of philosophical ideas. Therefore the following discussion 
Nursing Inquiry Main document R1 1.5.18

is organised according to some key philosophical touchstones, the body object; sense of self and identity and temporality with the aim of shining further light on the meanings of living within ageing skin in relation to existential aspects of ageing. These three particular emphases point to intertwined aspects of living within an ageing skin that emerged as important everyday features for our participants. We argue that these dimensions are central to the characteristisation of the experience of living with ageing skin and offer a theoretically informed ground to understand both the biological and the existential conditions that older people experience.

Body object dimensions: biological changes

The findings point to the experience of ageing skin in ways that are both 'body object' and 'body subject'. Skin changes were noticed by some in a continuous decline kind of way, others at pivotal moments in life events, for others a step wise decline. Physical manifestations included changes in sights and sensations. Skin texture altered and skin looked more rough and dry. Wrinkles appeared and, for some, blemishes and patchy pigmentation. The skin was a wider entity including appendages such as hair and nails. Skin was integral to the body, a part of the whole.

Appearance was important to our participants but was contained. The literature offers much discussion about older people's, most often older women's, approach to their appearance and the views presented are complex and sometimes contradictory. Martin, Leary, and Rejeski (2000) suggest that older people engage in strategic self-presentation and when they are met with ageist perceptions from others they increase their efforts to look younger. Macia et al. (2015) describe older women trying to 'escape time' and look young whilst viewing the extremes of such activity, such as cosmetic surgery, as unacceptably stigmatising; her participants were deeply ambivalent about cosmetic procedures labelling them as 'ridiculous' or 'pathetic'. 'Beauty work' is part of a lifelong investment in appearance (Hurd Clarke \& Griffin, 2008) and in common with our participants not something to be abandoned with increasing age. The notion of invasive procedures to enhance 
Nursing Inquiry Main document R1 1.5.18

appearance is debated, in our study it was discounted by all, however some report that older women are becoming increasingly amenable to surgical intervention (Hurd Clarke, 2010; Muise \& Desmarais, 2010; Slevin, 2010).

Liechty and Yarnal (2010) suggest that over the life-course women begin to de-prioritise their appearance and place more emphasis on health and internal characteristics. Conversely it is suggested that whilst women espouse health as more important than looks, interviews revealed their internalisation of ageist beauty norms despite their talk of the naturalness of the ageing process (Hurd Clarke, 2000). While aesthetic aspects emerged in older peoples' descriptions, youth and beauty did not specifically emerge from our participants, rather an acceptance and making the most of one's appearance seemed to be very important. The older people in our study did not go as far as desiring cosmetic or plastic surgery interventions, the findings reflected existing literature about the undesirability of pursuing 'eternal youth' (Jankowski et al., 2016). It would be of interest to explore the differences between older people and younger people in this regard, particularly in light of increasing evidence of younger people's desire for surgical solutions.

Bodily changes were noticed by our participants both directly related to the skin surface, such as wrinkles and altered pigmentation. Equally they reported wider issues such as greying hair and the whole body becoming flabbier. This has parallels with other studies in which participants placed importance on broader physical manifestations of weight gain, greying hair and facial hair (Winterich, 2007) and changes in body composition such as an increasing proportion of body fat (McKinley, 2006). Over time women tend to report more negative body image than men (Dumas et al., 2005) although evaluation of their older body by women is thought by some to shift from an aesthetic focus to a more functional understanding (Hurd Clarke \& Korotchenko, 2011). Whilst our participants cared about changes to both body and skin they were generally accepting of the 
Nursing Inquiry Main document R1 1.5.18

changes. In physical terms they valued skin functioning whilst being aware of the new and increasing fragility of the skin.

Identity Dimensions: sense of self

Sense of self in relation to ageing skin, and dimensions of identity emerged strongly, with sometimes new found freedom from the burdens of appearances. Life can be harsh for older people. We live in a youth oriented culture (Marinova, 2013) in which a youthful appearance is considered 'good, desirable and beautiful' (Healy, 1993). Older people are judged not by how old they are, but how young they are not (Twigg, 2004). Existing literature emphasises very negatively aspects of ageing appearance using dispiriting terminology, for example 'bad, repulsive and ugly' (Healy, 1993) and describing the 'bat wings and turkey wattles' that are a feature of ageing (Hurd Clarke et al., 2009). Twigg (2004) suggests that as we age we begin 'reading our bodies anxiously for signs of decay and decline'; this can start at any time in life and points to living within an ageing skin being not just a vulnerability of the old, it is relevant to us all. Our participants presented a less acute perception of ageing, they were aware of their changing place in society and how they were viewed by others but their thoughts on this were more equivocal. They did not necessarily like the skin changes and whilst they talked of them in terms of wrinkles, flab and rough, dry skin their negativity was not as extreme, their changing skin was just part of life.

What constitutes acceptable self-presentation is a continuum; for some what matters is being 'clean and tidy' (Jankowski et al., 2016), for others it is about being respectable (Clarke \& Bundon, 2009) whilst a proportion strive to be the best they can, investing significant time and effort in their appearance (Macia et al., 2015). Hurd Clarke and Griffin (2008) suggests that to avoid invisibility in society older women are 'compelled' to mask chronological changes though the use of beauty work. Our participants seemed to engage in cosmetic efforts far more for their own personal satisfaction than for the outside world, although some were influenced by pressure from their adult children. 
Nursing Inquiry Main document R1 1.5.18

This mirrors the idea advanced by McCormick and Marie (2008) of the dimension of the body being both body-for-self and body-for-others and the tensions of body as a private domain that is simultaneously functioning in the public domain, free to be scrutinised by others. Hurd Clarke et al. (2009) describes women attempting to compensate for bodily changes, for example, altering shape and sagging flesh by careful clothing choices to cover the offending areas. Our participants did not necessarily like the bodily changes experienced and many made efforts to conceal them particularly in public, but they did not significantly impact on lifestyle. In common with other literature our participants spoke of a certain inner confidence and acceptance that comes with age (Baker \& Gringart, 2009; Öberg \& Tornstam, 1999). In common with the work of Bullington (2006) and Hogan and Warren (2012) our study suggests that some people experience ageing as a time of freedom, of liberation from the pressure to conform to cultural norms, to be themselves.

Most appearance related literature in older age focuses on women and implies that they are far more affected by outward signs of ageing than men. It is often thought that women have more negative experiences of ageing due to societal norms (Hurd Clarke \& Korotchenko, 2011). Krekula (2016) challenges the idea that ageing is more painful and shameful for women than men because women are expected to live up to youthful beauty norms and our study, like that of Janowski et al. (2016), found the gender boundaries more blurred. As Hurd Clarke and Korotchecko (2011) suggest gender is only one dimension of complex phenomenon of ageing.

\section{Temporal Dimension: sense of continuity}

The findings reveal that the experience of living within an ageing skin has to do with a changing lifeworld which include important temporal dimensions. The responses of older people to their changed lifeworld intertwined with observable changes to their body surface carries implications for self. A key finding concerned how this changed skin, was no longer me, that is a me from my past, but rather required an adjustment to a new older me, that on occasions reminded older people in 
Nursing Inquiry Main document R1 1.5.18

the study of family elders from the past when they themselves were younger. The findings also point to some ways in which older people strived to come to terms with, or found a 'letting be' in their changed situation, this included taking extra care of the skin and a focus on either putting more effort into or letting go completely of an aesthetic dimension to skin care and presentation. Some experiences of ageing skin gave rise to perceptions about how unattractive the skin had become and a range of adaptive practices to mediate ageing effects and to make the best of skin appearance 'as it is now', were adopted. The older people in this study sometimes pointed to a certain kind of resoluteness in making the best of their ageing skin situation with a determination to continue living life as fully as possible, facing the world as an older me. These findings may offer insights for the care of older people that are deeper and more encompassing than mere biological skin care, skin care strategies were ways of embracing skin changes in as much as they were ways of making the most of oneself to face the world with others. At times there were negative experiences of self, but living in an ageing skin did not always mean a negative experience of sense of self, even if some feelings of loss, humour or frustration were expressed. The findings also pointed to how older people were in touch with the brute fact that 'death was approaching'.

Philosophical examination can help us understand our findings more deeply. For instance, Svenaeus draws on Heidegger's 'Being and Time' (Heidegger, 1962) and the 'Zollikon Seminars'(Heidegger, 2001) to progress a view of health as 'homelike being-in-the world'. He says: 'Health is to be understood as a being-at-home that keeps the not-being-at-home in the world from becoming apparent' (Svenaeus, 2000: 93). Although ageing skin was at first or often 'uncanny' ('unhomelike') older people often came to terms with ageing, sharing examples of how they became more at home 'in their own skin' to varying degrees. 
Nursing Inquiry Main document R1 1.5.18

\section{Conclusion}

The findings point to how older people experience their ageing skin as part of a much bigger concern of how they are in the world. The experience of living with ageing skin is highly complex, goes beyond the skin as 'body object' that incudes temporal, social and identity dimensions. These insights that are more than the mere biological have several implications for nursing care from the exceedingly practical, through to existential issues in older person care, and the need to be sensitive to these deeper concerns in practice. The literature about older people and skin is overly negative, however our findings reveal that for older people their identity is not necessarily tightly bound to beauty or external judgements of the aesthetic but rather to the continuities with earlier phases of life. Understandings of this sense of continuity is closely linked with a 'sense of personal journey', a core dimension of what it is to be human. Therefore these findings usefully point to directions for practice in how we can treat older people as persons by not overemphasising a view that focuses on bodies with aged skin alone, but rather, tempering this view with deeper lifeworld oriented insights about what it is like for older people in temporal ways and in their sense of self. In other words, deeper existential insights open up ways in which nurses can attend to meeting the older person with a skin care need as a person and not just a physical entity.

Secondly, there may be policy implications for ageing society. Most policy concerning ageing skin is necessarily concerned with safety for example the prevention pressure area damage, management and care of chronic leg ulcers and other long term skin conditions. However there is also a need for policy development that takes account of the lived experience of older people and prepares nurses to support older people with inevitable ageing skin and the impacts of growing older in an ageing body. Our findings indicate that older people are very aware of skin fragility and want to protect their skin, the findings offer practical directions in practice of skin care and in managing 'inevitability'. However the intricacies of skin care, if it is to be person centred, requires physical aspects education but also knowledge about the meaning of growing older so that nurses can offer a 
Nursing Inquiry Main document R1 1.5.18

high degree of human sensitivity when working with older people. Thirdly, In relation to the phenomenon of living in an ageing skin, we wish to point to the how 'the unhomeliness' of ageing skin, is apparent in our findings through process of skin becoming an object of attention, due to ageing surface changes. However this bodily 'uncanniness', although perhaps never fully resolved, can become embraced and accepted within the possibility of finding ageing skin more homelike, or to put it another way, more 'at home in one's own skin'. The older people in this present study shared poignant examples, such as continuities with sense of self; being in touch with life on the inside as continuous with youth; making the most of one's situation and appearance, and the continuities given by recognising their elders in their now aged selves. These are instances of finding home, a particular kind of settledness within the unhomelike later phases of life and can be considered a core aspect of wellbeing, it could be argued that this letting be offers one pathway to the deepest possibilities of a sense of well-being within ageing. We argue, such insights are useful existential directions for practice that go beyond biological care of the skin and such a lifeworld perspective opens up potential strategies to support people in ageing. 


\section{References}

Adam, J.E., \& Reilly, S. (1987). The prevalence of skin disease in the geriatric age group. The Australasian Journal of Dermatology, 28, 72-76.

Baker, L., \& Gringart, E. (2009). Body image and self-esteem in older adulthood. Ageing \& Society, 29, 977-995.

Beeckman, D., Van Lancker, A., Van Hecke, A., \& Verhaeghe, S. (2014). A systematic review and meta-analysis of incontinence-associated dermatitis, incontinence, and moisture as risk factors for pressure ulcer development. Research in Nursing \& Health, 37, 204-218.

Blume-Peytavi, U., Kottner, J., Sterry, W., Hodin, M.W., Griffiths, T.W., Watson, R.E., Hay, R.J., \& Griffiths, C.E. (2016). Age-associated skin conditions and diseases: current perspectives and future options. The Gerontologist, 56, (Suppl 2), S230-S242.

Bullington, J. (2006). Body and self: a phenomenological study on the ageing body and identity. Medical Humanities, 32, 25-31.

Carville, K., Leslie, G., Osseiran-Moisson, R., Newall, N., \& Lewin, G. (2014). The effectiveness of a twice-daily skin-moisturising regimen for reducing the incidence of skin tears. International Wound Journal, 11, 446-453.

Cowdell, F., Jadotte, Y.T., Ersser, S.J., Danby, S., Walton, S., Lawton, S., Roberts, A., Gardiner, E., Ware, F., \& Cork, M. Hygiene and emollient interventions for maintaining skin integrity in older people in hospital and residential care settings (Protocol). Cochrane Database of Systematic Reviews 2014, Issue 12. Art. No.: CD011377. DOI: 10.1002/14651858.CD011377.

Cowdell, F., \& Steventon, K. (2015). Skin cleansing practices for older people: a systematic review. International Journal of Older People Nursing, 10, 3-13.

Dahlberg, K. (2011). Lifeworld phenomenology for caring and for health care research. In G. Thomson, F. Dykes \& Downe, S (Eds.) Qualitative research in midwifery and childbirth, phenomenological approaches (pp. 19-34). London: Routledge.

Dahlberg, K., Todres, L., \& Galvin, K. (2009). Lifeworld-led healthcare is more than patient-led care: An existential view of well-being. Medicine, Health Care and Philosophy, 12, 265-271.

Dahlberg, K., Nyström, M., \& Dahlberg, H. (2008). Reflective Lifeworld Research. Lund: Studentlitteratur.

Drummond, M.J. (2003). Retired men, retired bodies. International Journal of Men's Health, 2, 183.

Dumas, A., Laberge, S., \& Straka, S.M. (2005). Older women's relations to bodily appearance: the embodiment of social and biological conditions of existence, Ageing \& Society, 25, 883-902.

Fleischer, A.B., McFarlane, M., Hinds, M.A., \& Mittlemark, M. (1996). Skin conditions and symptoms are common in the elderly: the prevalence of skin symptoms and conditions in an elderly population. Journal of Geriatric Dermatology, 4, 78-87. 
Galvin, K., \& Todres L. (2011) Kinds of wellbeing: a conceptual framework that provides direction for caring International Journal of Qualitative Studies in Health and Wellbeing, DOI:

10.3402/qhw.v6i4.10362

Galvin, K.T., Cowdell, F., Sloan, C., Pound, C., Ellis-Hill, C., Ersser, S., Watson, R., \& Brooks, S. (2016) Humanising services: A new transferable leadership strategy for improving 'what matters to older people' to enhance dignity in care. Project report Burdett Trust for Nursing. Retrieved from http://www.btfn.org.uk/our-reports/

Goldberg, E. (2005). The lived experience of living with a chronic wound: a phenomenologic study. MedSurg Nursing, 14, 51-55.

Hamill, C., \& Sinclair, H.A. (2010). Bracketing-practical considerations in Husserlian phenomenological research: Conal Hamill and Helen Sinclair discuss bracketing in Husserlian phenomenological research. Nurse Researcher, 17, 16-24.

Hamilton, C. (2016). 'This damnable, disgusting old age': In G. Scarre, \& G. Scarre. (Eds.) Ageing and (being) one's body. (pp. 305-324). New York, NY: Palgrave Macmillan.

Healy, S. (1993) Confronting ageism: a MUST for mental health. In N. Davis, E. Cole, E. Rothblum (Eds.) Faces of Women and Aging. (pp. 41-54). New York: Harrington Park.

Heidegger, M. (1927/1962). Being and time (J. Macquarrie \& E. Robinson, Trans.). Oxford, UK: Blackwell.

Heidegger, M. (2001). Zollikon seminars (M.Boss, Ed., F.Mayr \& R. Askay, Trans.). Evanston, IL: Northwestern University Press.

Hofmeier, S.M., Runfola, C.D., Sala, M., Gagne, D.A., Brownley, K.A., \& Bulik, C.M. (2017). Body image, aging, and identity in women over 50: The gender and body image (GABI) study. Journal of Women \& Aging, 29, 3-14.

Hogan, S., \& Warren, L. (2012). Dealing with complexity in research processes and findings: How do older women negotiate and challenge images of aging? Journal of Women \& Aging, 24, 329-350. Hopkins, A., Dealey, C., Bale, S., Defloor, T., \& Worboys F. (2006) Patient stories of living with a pressure ulcer. Journal of Advanced Nursing, 56, 345-353.

Hurd Clarke, L. (2000). Older women's body image and embodied experience: An exploration. Journal of Women \& Aging, 12, 77-97.

Hurd Clarke, L. (2002). Beauty in later life: Older women's perceptions of physical attractiveness. Canadian Journal on Aging, 21, 429-442.

Hurd Clarke, L., \& Griffin, M. (2007). The body natural and the body unnatural: Beauty work and aging. Journal of Aging Studies, 21, 187-201.

Hurd Clarke, L., \& Griffin, M. (2008). Visible and invisible ageing: Beauty work as a response to ageism. Ageing \& Society, 28, 653-674.

Hurd Clarke, L., \& Bundon, A. (2009). From 'the thing to do' to 'defying the ravages of age': Older women reflect on the use of lipstick. Journal of Women \& Aging, 21, 198-212. 
Hurd Clarke, L., Griffin, M., \& Maliha, K. (2009). Bat wings, bunions, and turkey wattles: body transgressions and older women's strategic clothing choices. Ageing \& Society, 29, 709-726.

Hurd Clarke, L. (2010) Facing age: Women growing older in an anti-aging culture. Toronto: Rowman and Littlefield.

Hurd Clarke, L., \& Korotchenko, A. (2011). Aging and the body: A review. Canadian Journal on Aging, 30, 495-510.

Husserl, E. (1998). The Paris Lectures. Netherlands, Springer.

Hyde, C., \& Ward B. (1999) Older women's experience of living with chronic leg ulceration. International Journal of Nursing Practice, 5, 189-198.

Jankowski, G.S., Diedrichs, P.C., Williamson, H., Christopher, G., \& Harcourt, D. (2016). Looking ageappropriate while growing old gracefully: A qualitative study of ageing and body image among older adults. Journal of Health Psychology, 21, 550-561.

Johansson, K., Ekebergh, M., \& Dahlberg, K. (2009). A lifeworld phenomenological study of the experience of falling ill with diabetes. International Journal of Nursing Studies, 46, 197-203.

Kirkup, M. (2008). Itching in elderly people. Geriatric Medicine, 38, 671.

Kottner, J., Lichterfeld, A., \& Blume-Peytavi, U. (2013). Maintaining skin integrity in the aged: a systematic review. British Journal of Dermatology, 169, 528-542.

Krekula, C. (2016). Contextualizing older women's body images: Time dimensions, multiple reference groups, and age codings of appearance. Journal of Women \& Aging, 28, 58-67.

Leder, D. (1990) The absent body. Chicago. University of Chicago Press.

Leder, D. (1992) The body in medical thought and practice. Dordrecht: Kluwer Academic Publishers.

Liechty, T. \& Yarnal, C.M. (2010). Older women's body image: A lifecourse perspective. Ageing \& Society, 30, 1197-1218.

Liechty, T. (2012). 'Yes, I worry about my weight... but for the most part I'm content with my body': older women's body dissatisfaction alongside contentment. Journal of Women \& Aging, 24, 70-88.

Lindberg, E., Österberg, S.A., \& Hörberg, U. (2016). Methodological support for the further abstraction of and philosophical examination of empirical findings in the context of caring science. International Journal of Qualitative Studies on Health and Well-being, 11, 30482.

Macia, E., Duboz, P., \& Chevé, D. (2015). The paradox of impossible beauty: body changes and beauty practices in aging women. Journal of Women \& Aging, 27, 174-187.

Marinova, D. (2013). Cultural alienation in the ageing person. Psychological Thought, 6, 264-282.

Martin, K.A., Leary, M.R., \& Rejeski, W.J. (2000). Self-presentational concerns in older adults: Implications for health and well-being. Basic and Applied Social Psychology, 22, 169-179. 
McCormick, M. L. (2008) 'My body my 'self': Aging and the lived experience of embodied womanhood'. Retrieved from http://fordham.bepress.com/dissertations/AAl3309584

McKinley, N.M. (2006). The developmental and cultural contexts of objectified body consciousness: a longitudinal analysis of two cohorts of women. Developmental Psychology, 42, 679.

Merleau-Ponty, M. (1962). Phenomenology of Perception, trans, C. Smith. London: Routledge

Moore, Z.E.H., \& Cowman, S. Repositioning for treating pressure ulcers. Cochrane Database of Systematic Reviews 2015, Issue 1. Art. No.: CD006898. DOI: 10.1002/14651858.CD006898.pub4

Muise, A., \& Desmarais, S. (2010). Women's perceptions and use of 'anti-aging' products. Sex Roles, 63, 126-137.

Öberg, P., \& Tornstam, L. (1999). Body images among men and women of different ages. Ageing \& Society, 19, 629-644.

Paul, C., Maumus-Robert, S., Mazereeuw-Hautier, J., Guyen, C.N., Saudez, X., \& Schmitt, A.M. (2011). Prevalence and risk factors for xerosis in the elderly: a cross-sectional epidemiological study in primary care. Dermatology (Basel, Switzerland), 223, 260-265.

Paulson, S., \& Willig, C. (2008). Older women and everyday talk about the ageing body. Journal of Health Psychology, 13, 106-120.

Svenaeus, F. (2000). The hermeneutics of medicine and the phenomenology of health: Steps towards a philosophy of medical practice. London, UK: Kluwer Academic Publishers.

Slevin, K.F. (2010). 'If I had lots of money... I'd have a body makeover:' Managing the aging body. Social Forces, 88, 1003-1020.

Todres, L., \& Galvin, K.T. (2008). Embodied interpretation: A novel way of evocatively re-presenting meanings in phenomenological research. Qualitative Research, 8, 568-583.

Todres, L., \& Galvin, K.T. (2012) In the middle of everywhere': a phenomenological study of mobility and dwelling amongst rural elders Phenomenology and Practice, 6, 55-68.

Todres, L., Galvin, K.T., \& Dahlberg, K. (2014). 'Caring for insiderness': Phenomenologically informed insights that can guide practice. International Journal of Qualitative Studies on Health and Wellbeing, 9, 21421.

Toombs, S.K. (2001). Handbook of phenomenology and medicine. USA. Springer Science \& Business Media.

Twigg, J. (2004). The body, gender, and age: Feminist insights in social gerontology. Journal of Aging Studies, 18, 59-73.

United Nations, Department of Economic and Social Affairs, Population Division. (2013). World Population Ageing 2013. Retrieved from http://www.un.org/en/development/desa/population/

Voegeli, D. (2008). The effect of washing and drying practices on skin barrier function. Journal of Wound, Ostomy \& Continence Nursing, 35, 84-90. 
Nursing Inquiry Main document R1 1.5.18

Winterich, J.A. (2007). Aging, femininity, and the body: What appearance changes mean to women with age. Gender Issues, 24, 51-69.

Yeslev, M., Gupta, V., Winocour, J., Shack, R.B., Grotting, J.C., \& Higdon, K.K. (2015). Safety of cosmetic procedures in elderly and octogenarian patients. Aesthetic Surgery Journal, 35, 864-873. 